\title{
Conhecimento Científico
}

\author{
Scientific Knowledge
}

\section{Rogério Parentoni Martins ${ }^{1, *}$ \& Francisco Ângelo Coutinho ${ }^{2}$}

\author{
${ }^{1}$ Departamento de Biologia, Centro de Ciências, Universidade Federal do Ceará - UFC \\ ${ }^{2}$ Departamento de Métodos e Técnicas de Ensino, Faculdade de Educação, Universidade Federal de Minas Gerais - UFMG
}

Quando admitimos que algo seja conhecido ou, em nosso caso, cientificamente válido, deixamos implícito que sabemos precisamente o significado de conhecer. Ou achamos que sabemos. Dúvidas sobre a natureza do conhecimento as há desde as primeiras reflexões ocidentais sobre o tema, iniciadas na Grécia Antiga. A história da filosofia do conhecimento é, portanto, antiga e marcada por diversos momentos importantes, mas que não cabe aqui serem discutidos (ver Coutinho 2002, para tal discussão).

Por serem contemporâneas e abrangentes, talvez nos interessem mais as reflexões de alguns filósofos da ciência do século XX: Karl Popper, Irme Lakatos, Thomas Kuhn e Paul Feyrabend. Mas, à exceção de Popper, as reflexões dos demais não tiveram impacto significativo entre os biólogos. Por isso e por também ter de certa forma influenciado o modo de desenvolvimento dos trabalhos científicos em Ecologia no Brasil, discutiremos brevemente o contexto do conhecimento ecológico em nosso país sob a perspectiva da epistemologia popperiana. Popper começou a ser lido tardiamente no Brasil, por isso o impacto de suas idéias sobre a biologia brasileira repercutiu muito no meio acadêmico brasileiro, especialmente nos anos 1980.

Um dos objetivos de Popper foi o de estabelecer critérios para demarcar o que é conhecimento científico, distinguindo-o de outros tipos de conhecimento tal qual o adquirido por meio da fé ou da arte. E o fez por intermédio da proposição de que o conhecimento científico ou uma teoria científica só poderia ser válida se fossem elaboradas hipóteses (afirmativas sobre a natureza ou causalidade de fenômenos ecológicos) que pudessem ser refutadas ou falsificáveis. Se uma hipótese resiste à refutação, após suas previsões terem sido exaustivamente testadas, o conhecimento que a afirmação propõe está corroborado e é o mais provável de ser próximo da verdade (verossimilhança), pois a verdade absoluta é inatingível tanto davido às limitações de nossos

\footnotetext{
*Send correspondence to: Rogério Parentoni Martins Departamento de Biologia, Centro de Ciências, Universidade Federal do Ceará - UFC, Fortaleza, CE, Brasil E-mail: wasp@icb.ufmg.br
}

sentidos perceptivos, quanto pelas limitações na estrutura abstrata de nossas teorias. Em contraste, o conhecimento adquirido por intermédio da fé não é passível de refutação empírica e, por isso, fica fora do âmbito da ciência.

Por outro lado, muitos ecólogos adotaram um tanto entusiasticamente o método "strong inference" (Platt 1964) pelo qual se testa as previsões de uma hipótese considerada pelo pesquisador como a mais plausível, mas também se testa previsões de outras hipóteses teoricamente também plausíveis (ver também Martins \& Coutinho 2004). Em primeiro lugar, testam-se as previsões menos plausíveis e se uma a uma forem descartadas, a elegida pelo pesquisador como a mais plausível, torna-se extremamente "forte" como uma explicação causal de determinado fenômeno. No entanto como o próprio Platt adverte, sua proposta metodológica seria adequada apenas em condições experimentais controladas, a exemplo das que são realizadas pelos físicos. No entanto, muitos ecólogos a ignoraram.

Contudo, retornando a Popper, como é comum quando surgem novidades, os ânimos de vários pesquisadores brasileiros, e não apenas brasileiros, se exaltaram até um ponto tão extremo de se tornarem cegamente hiperpopperianos, ou seja, mais intensamente popperianos que o próprio. Este foi o caso de um pesquisador norteamericano, com que um dos autores teve um curto, mas significativo diálogo. Ele achava que estaria resolvido o problema do conhecimento em ecologia, pois seria possível tornar a ecologia parecida com a física, o xodó dos filósofos do conhecimento. E isso se daria pela aplicação rigorosa do método hipotético-dedutivo, que atribuía a Popper. Enfim, tudo em ecologia que não seguisse o método seria uma ciência de segunda categoria e, portanto, a nosso ver, preconceituosamente, relegada a segundo plano. Ora, com isso ele estava desdenhando excelentes estudos de naturalistas presentes e passados, inclusive aqueles que pavimentaram o caminho para a construção da ciência ecológica (Kingsland 1991). Outro episódio significativo foi o de um zoólogo brasileiro entusiasmado pela sistemática filogenética, que na época se difundia pelo Brasil. Dizia o pesquisador, com 
ironia, que Ecologia, segundo Popper, não era ciência e que ciência de fato era a sistemática filogenética, pois a ecologia não tinha hipóteses falsificáveis. Tais atitudes extremistas ensinaram-nos que seria contraproducente ignorar outras opções válidas para construção do conhecimento ecológico, pois uma atitude pluralista enriqueceria as possibilidades de sua ampliação. Aprendemos também que tais posturas extremistas não contribuem para o aprimoramento das reflexões e elaboração de teorias abrangentes e consistentes.

Mais recentemente, o filósofo Lipton (2005) resolveu examinar quais seriam as vantagens de se iniciar um trabalho científico formulando em primeiro lugar hipóteses ou, em contrapósição, iniciá-lo a partir de um conjunto de dados e só então formular uma hipótese explicativa, induzindo uma generalização (em suas palavras 'acomodação' dos dados, sem significado pejorativo). A conclusão é a de que devido à possibilidade de ocorrer "maquiagem" dos dados, contida na acomodação, há uma tendência de os cientistas aceitarem mais o método de previsão de hipóteses previamente formuladas. Porém, ambos os tipos de conhecimentos gerados pela aplicação de cada um dos dois métodos seriam confiáveis e igualmente válidos. Por outro lado, um argumento não considerado por Lipton (2005) é o de que formular hipóteses previamente poderá economizar tempo e dinheiro empregados para realização da pesquisa. Mais uma vez, isso não significa que formular hipóteses a posteriori seja um "crime" praticado contra a "imaculada” Ciência.

Finalmente, essa "popperização" excessiva provocou também reações contrárias no Brasil. Um físico, claramente irritado com a aplicação suprema do critério de falseamento, publicou um artigo em jornal contestando Popper quando este rotulou evolução, marxismo e freudianismo como metafísica. Ou seja, a garantia da autenticidade do conhecimento seria a possibilidade de ser refutado e, na análise de Popper, esses conhecimentos não a apresentavam, daí não serem científicos. O físico concluiu o trabalho dizendo que ciência é o que o cientista faz: uma opinião peculiar e simpática e, de certa forma, alinhada à epistemologia de Thomas Kuhn, mas também sujeita a discussões, pois é necessário explicitar como os cientistas fazem ciência. Apesar disso, ele não deixa de ter certa razão na prática científica cotidiana. $\mathrm{O}$ conhecimento científico em ecologia, previamente à sua publicação, sofre críticas de revisores que certificam a qualidade e veracidade do mesmo. Portanto, é esta crítica feita por pares que legitima o conhecimento proposto.

Por outro lado, considerando-se que nossos sentidos são insuficientes para processar e entender a natureza de certos fenômenos "invisíveis", formular teorias é o meio de que dispomos para adquirir conhecimento sobre o que supomos possa acontecer, mas temos dificuldade de visualizar. Não há relatos de quem tenha visto seleção natural, empurrando um macaco de uma árvore ou a gravitação universal como se fosse um monte de fios estabelecendo conexões entre dois corpos. Mas, teoricamente, supomos que entidades teóricas tais como gravitação universal e seleção natural possam ser bons instrumentos para compreendermos respectivamente diversos fenômenos físicos e biológicos.

Tendo em vista a utilidade da teoria para o aprimoramento do conhecimento ecológico, cabe-nos discutir sobre a estrutura de teorias a fim de que possamos entender sua utilidade, aprimorá-la e até mesmo construir teorias mais abrangentes (Pickett et al. 2007). A história da ciência em geral e também em ecologia (Kingsland 1991) está repleta de exemplos. Basta citar o caso da deriva dos continentes e a concepção moderna baseada na tectônica de placas. Aliás, nesse caso, comparações entre faunas de mamíferos, filogeneticamente distintas, em florestas equatoriais africana e brasileira, mas morfológica e ecologicamente convergentes, foram importantes para reforçar a hipótese de que os continentes se derivaram, um fenômeno absolutamente “invisível”. Nesse caso, como também em vários outros, a partir de evidências que podem ser interpretadas que ocorreram por causa de determinado fenômeno, infere-se a sua veracidade.

Richard Levins (1968), disse que há três ingredientes que deveriam fazer parte de uma teoria ideal: generalização, precisão e realismo. Generalização é o que almeja qualquer cientista que formule uma teoria. Quanto mais geral for, maior número de casos particulares em seu domínio seria por ela explicado. A teoria de evolução por meio da seleção natural, que é geral, diz respeito a qualquer organismo, explica modificações que organismos sofrem em cada geração, cujas modificações selecionadas podem se tornar adaptações em integrantes de gerações posteriores. Se há variação entre atributos individuais em uma população, por exemplo, tamanho, e se indivíduos de tamanhos relativamente menores sobreviverem e reproduzirem mais, relativamente aos de tamanho maiores, haverá uma tendência em predominar indivíduos menores nas gerações posteriores, desde que tamanho seja geneticamente determinado. Todavia, embora possa ser considerada uma teoria madura, ainda não são conhecidos detalhes de como a seleção natural atua em condições naturais, faltando-lhe, portanto, realismo. Em contraste, há teorias configuradas para situações mais aplicadas como, por exemplo, em agroecologia, que lidam com situações tão específicas, que lhes falta generalização, mas têm precisão e realismo, pois incluem em sua estrutura detalhes que lhe garantem essas características. No entanto, tais teorias só terão validade nas condições específicas para as quais foram configuradas. Nesse caso, por exemplo, um modelo computacional que inclua numerosas variáveis poderia ser uma teoria para explicar um fenômeno em um domínio bem restrito e, portanto inválida para outras situações em outros locais e em outros tempos. Enfim, há teorias e teorias e, por isso, devemos reconhecer uma pluralidade de estados em uma teoria. Uma teoria em estado nascente, por exemplo, pode ter em sua estrutura, apenas uma hipótese. Mas não deixa de ser uma teoria. Com o seu desenvolvimento por meio da incorporação de fatos, definições, conceitos, generalizações, modelos e leis ela poderá tornar-se uma teoria consistente, madura 
e assim reconhecida e legitimada pela grande maioria dos cientistas da área (Pickett et al. 2007).

Scheine \& Willing (2008) propõem uma teoria geral para ecologia que inclua todas as teorias existentes as quais chamam teorias constituintes. Embora não tenham formulado rigorosamente tal teoria, defendem que ela consista na descrição do domínio da ecologia e um conjunto de princípios fundamentais. O domínio da ecologia seria os padrões temporais e espaciais de distribuição e abundância de organismos, incluindo as causas e conseqüências. Os princípios fundamentais são afirmações amplas a respeito dos padrões e dos processos que operam no âmbito do domínio. Os sete princípios fundamentais (são fundamentais, pois as proposições de quaisquer teorias em ecologia podem ser verificadas como uma conseqüência desses princípios e de outros provenientes do domínio de outras ciências, o que seria um modo de translação; ver Pickett et al. 2007 ) são: (1) os organismos se distribuem de forma heterogênea no tempo e espaço; (2) Organismos interagem com seu ambiente biótico e abiótico; (3) A distribuição dos organismos e de suas interações é contingencial; (4) Condições ambientais são heterogêneas no tempo e espaço; (5) Recursos são finitos e heterogêneos no tempo e espaço; (6) Todos os organismos são mortais e (7) as propriedades ecológicas de espécies resultam do processo evolutivo. Se refletirmos e verificarmos, de fato todas as teorias da ecologia tem a ver com esses sete princípios, e a tarefa de integrar todas as teorias constituintes em um arcabouço teórico único e coeso é tarefa formidável. No entanto, esse trabalho indica que a ecologia está a caminho de uma fase de maturidade como disciplina científica.
Finalmente, conhecer a história e um pouco da filosofia da ciência de sua área de pesquisa é importante para os que estão dispostos a refinar suas pesquisas e alcançar resultados coerentes, significativos e de qualidade. Nesse processo de aquisição de conhecimento, discutir as dúvidas e questionar os conhecimentos estabelecidos são combustíveis para o crescimento intelectual e científico.

\section{Refêrencias}

Coutinho FA, 2002. Conhecimento. In: Martins RP \& Mari $\mathrm{H}$ (Ed.). Universos do Conhecimento. Belo Horizonte: Faculdade de Letras da UFMG. p. 91-115.

Kingsland S, 1991. Defining ecology as a science. In: Real LA \& Brown JA. Foundations of Ecology. London: The University of Chicago Press. p. 1-13.

Levins R, 1968. Evolution in Changing Environments. Princeton: Princeton University Press.

Lipton P, 2005. Testing hypothesis: prediction and prejudice. Science, 317:219-221.

Martins RP \& Coutinho FA, 2004. O Fantasma Teoria. In: Coelho AS, Loyola RD \& Souza MBG (Ed.). Ecologia Teórica: desafios para o aperfeiçoamento da Ecologia no Brasil. Belo Horizonte: O Lutador. p. 15-26.

Pickett STA, Kolasa J \& Jones CG, 2007. Ecological Understanding. Amsterdam: Elsevier.

Platt JR, 1964. Strong inference. Science, 146:346-353.

Scheine SM \& Willing MR, 2008. A general theory of ecology. Theoretical Ecology, 1:21-28.

Recebido: Agosto 2010

Primeira Decisão: Setembro 2010

Aceito: Setembro 2010 